\title{
Oceaniglobus Trochenteri sp. nov., Isolated from the Gut Microflora of top Shell (Trochus Maculatus Linnaeus).
}

\section{Zhuo Chen}

Shandong University

Shuai-ting Yun

Shandong University

Ming-jing Zhang

Shandong University

Rui Yin

Shandong University

Yan-Xia Zhou ( $\nabla$ zhouyx@sdu.edu.cn )

Shandong University https://orcid.org/0000-0003-0393-8136

\section{Research Article}

Keywords: Genomic Taxonomy, Marine creature, Oceaniglobus, Polyphasic analysis

Posted Date: July 15th, 2021

DOl: https://doi.org/10.21203/rs.3.rs-565381/v1

License: (c) (i) This work is licensed under a Creative Commons Attribution 4.0 International License. Read Full License 


\section{Abstract}

A Gram-stain negative, non-flagellated, beige-pigmented, circular, catalase-positive, oxidase-positive bacterium, designated $\mathrm{G}^{\top}{ }^{\top}$, was isolated from gut microflora of top shell (Trochus maculatus Linnaeus) collected from Diwanggong market, Weihai, PR China. The novel isolate was able to grow at $4-42^{\circ} \mathrm{C}$ (optimum $25-33^{\circ} \mathrm{C}$ ), $\mathrm{pH} 7.0-9.0$ (optimum $6.5-7.0$ ) and with $0.0-11.0 \% \mathrm{NaCl}$ (optimum $2.0-3.0 \%, \mathrm{w} / \mathrm{v}$ ). Analysis of $16 \mathrm{~S}$ rRNA gene sequence revealed that strain $\mathrm{G}^{\top}{ }^{\top}$ shared the highest $16 \mathrm{~S}$ rRNA gene sequence similarities with Oceaniglobus $\mathrm{YLYO8}^{\top}$ (96.6\%), followed by Oceaniglobus indicus $1-19 \mathrm{~b}^{\top}$ (95.3\%). The genome of strain $\mathrm{G} 4^{\top}$, with 32 assembled contigs, was $4.5 \mathrm{Mb}$ long with a $\mathrm{G}+\mathrm{C}$ content of $65.3 \mathrm{~mol} \%$. DNA-DNA hybridization values of the isolate against the closely related type strains were far below the $70 \%$ limit for species delineation. The average amino acid identity, average nucleotide identity and digital DNA-DNA genome hybridization relatedness between strain $\mathrm{G} 4^{\top}$ and the closely related members of the genus Oceaniglobus, Oceaniglobus indicus $1-19 \mathrm{~b}^{\top}$ and Oceaniglobus ichthyenteri $\mathrm{YLY}^{\mathrm{C}} \mathrm{8}^{\top}$ were $71.3,76.4$ and $20.0 \%$, and $75.0,76.3$ and $19.4 \%$. The major cellular fatty acid was summed feature 8 $\left(\mathrm{C}_{18: 1} \omega 7 c\right.$ and/or $\left.\mathrm{C}_{18: 1} \omega 6 c\right)$. The sole respiratory quinone detected was $\mathrm{Q}-10$. The polar lipid profile consisted of diphosphatidylglycerol, phosphatidylcholine, phosphatidylethanolamine, phosphatidylglycerol and phosphatidyldimethylethanolamine. The results of phenotypical, phylogenetic and biochemical analyses indicated that strain $\mathrm{G}^{\top}{ }^{\top}$ represents a novel species in genus Oceaniglobus within the family Rhodobacteraceae, for which the name Oceaniglobus trochenterisp. nov. is proposed. The type strain is $\mathrm{G}^{\top}\left(=\right.$ MCCC $1 \mathrm{KO} 0356^{\top}=$ KCTC $\left.82506^{\top}\right)$.

\section{Introduction}

Marine bacteria play an important role in marine ecology, many bacterial strains have been isolated and characterized taxonomically from coastal marine environments and marine organisms. The genus Oceaniglobus belongs to the family Rhodobacteraceae, was initially established by Li et al. (2017). At the time of writing, the genus Oceaniglobus consists of two species both from the marine environment, including Oceaniglobus indicus (type species) from sea water (Li et al. 2017) and Oceaniglobus ichthyenteri from the gut of sea bass (Wang et al. 2019). For researching bacterial diversity in the gut of top shell and isolating potential probiotics, we carried out a culture-dependent bacterial isolation from the gastrointestinal tract of Trochus maculatus Linnaeus. During this research, a novel bacterial strain was isolated and designated strain $\mathrm{G}^{\top}$. The aim of this study was to validate the existence of novel species of the genus Oceaniglobus on the basis of phylogenetic, genotypic and phenotypic data.

\section{Materials And Methods}

Isolation and culture conditions

For the bacterial isolation, the intestinal tissue sample was processed by an enriched culture technique (Du et al. 2014). The enriched culture (30 days) was diluted serially in sterile seawater and samples of 
each serial dilution were spread on marine agar 2216 (MA; Becton Dickinson) plates for cultivation at $28^{\circ} \mathrm{C}$. After incubation for a week, a beige-pigmented colony was picked up and subcultured several times to get a pure culture, later designated as strain $\mathrm{G} 4^{\top}$. The isolate was purified by repeated subculture and stored at $-80{ }^{\circ} \mathrm{C}$ in sterile $15 \%(\mathrm{v} / \mathrm{v})$ glycerol supplemented with $1 \%(\mathrm{v} / \mathrm{v}) \mathrm{NaCl}$. The type strains, Oceaniglobus indicus MCCC $1 \mathrm{~A} 11863^{\top}$ and Oceaniglobus ichthyenteri MCCC $1 \mathrm{H} 00318^{\top}$ were purchased from their respective collection institutions. All strains were cultured under comparable conditions for physiological and chemotaxonomic characterizations, unless otherwise specified. They were preserved at $-80^{\circ} \mathrm{C}$ in sterile distilled water supplemented with $1.0 \% \mathrm{NaCl}(\mathrm{w} / \mathrm{v})$ and $15.0 \%(\mathrm{v} / \mathrm{v})$ glycerol.

\section{Phylogenetic analysis and genome sequencing}

For $16 \mathrm{~S}$ rRNA gene sequencing and phylogenetic analysis, the genomic DNA of strain $\mathrm{G} 4^{\top}$ was extracted using a commercial genomic DNA extraction kit (Takara) according to the manufacturer's instructions. The 16S rRNA gene sequence was amplified by PCR with universal bacterial primers 27F and 1492R (Liu and Shao 2005). The PCR product was purified and cloned into PMD18-T vector (Takara) according to the manufacturer's instructions. Plasmids were sequenced using universal M13 primers. The identification of phylogenetic neighbours and the calculation of 16S rRNA gene sequence similarity were performed using the EzBioCloud tool (http://www.ezbiocloud.net/) (Kim et al. 2012) and the blast tool in the NCBI database (www.ncbi.nlm.nih.gov/blast/). Sequences of related taxa were obtained from the GenBank database. Based on 16S rRNA gene sequences, phylogenetic analysis was performed using mega version 7 (Kumar et al. 2016) with distance option according to the default parameter models and clustering with the neighbour-joining (Saitou and Nei 1986), maximum-parsimony (Fitch 1971) and maximum-likelihood (Felsenstein 1981) methods, with bootstrap values based on 1000 replications (Felsenstein 1985).

The draft genome of strain $\mathrm{G}^{\top}{ }^{\top}$ was sequenced at Beijing Novogene Bioinformatics Technology Co, Ltd. (Beijing, PR China), using a HiSeq-PE150 platform (Illumina) with massively parallel sequencing technology (Illumina). The genes involved in metabolic pathways were analyzed using the Kyoto Encyclopedia of Genes and Genomes (KEGG) databases (Kanehisa et al. 2016). Protein-encoding regions were identified and annotated with the Rapid Annotations using Subsystems Technology (RAST) server (http://rast.nmpdr.org/rast.cgi) (Aziz et al. 2008) and the UniProtKB/Swiss-Prot (Consortium 2019). Secondary metabolite was presented by antiSMASH 5.0 (Blin et al. 2019). The DNA G + C content of strain $\mathrm{G} 4^{\top}$ was determined from the genome sequence. Genomic data of other type strains within the family Rhodobacteraceae were obtained from the GenBank/ENA/DDBJ databanks. The average amino acid identity (AAl) values were calculated using EzBioCloud integrated database (Yoon et al. 2017a). Average nucleotide identity (ANI) values between two genomes were calculated using OrthoANlu algorithm (Yoon et al. 2017b). The digital DNA-DNA hybridization (dDDH) values were calculated using the Genome-to-Genome Distance Calculator (GGDC 2.0) (Meier-Kolthoff et al. 2013).

Morphology, physiology, and biochemical analysis 
The morphological and physiological characteristics of strain $\mathrm{G} 4^{\top}$ were observed on MA at $30{ }^{\circ} \mathrm{C}$ for 2 days. Cell morphology, size and the presence of flagella were examined by transmission electron microscopy (JEM-1200, JEOL). Gram reaction was determined as described by according to Park et al. (2014). The activities of catalase and oxidase, hydrolysis of cellulose, agar, casein, and Tween 80 , were tested according to the method of Tindall (2007). Hydrolysis of alginate was tested on MA with $0.2 \%$ $(\mathrm{w} / \mathrm{v})$ sodium alginate as described by Takeshita et al. (1991). Motility was determined using the hanging-drop method and gliding motility was determined as described by Bowman (2000). Temperaturedependent growth was tested at $4,10,15,20,25,30,33,37,40,42$, and $45^{\circ} \mathrm{C}$ on $\mathrm{MA}$. The $\mathrm{pH}$ range for growth was determined in $\mathrm{MB}$ adjusted to $\mathrm{pH}$ 5.5-9.5 with a concentration of $20 \mathrm{mM}$ using the following buffer systems: MES (pH 5.5 and 6.0), PIPES (pH 6.5 and 7.0), HEPES (pH 7.5 and 8.0), Tricine (pH 8.5), and CAPSO (pH 9.0 and 9.5). The effect of $\mathrm{NaCl}$ on growth was tested in $\mathrm{NaCl}$-free artificial seawater medium supplemented with $5.0 \mathrm{~g}$ peptone, $1.0 \mathrm{~g}$ yeast extract, and various concentrations of $\mathrm{NaCl}$ (final concentration $0.0-10.0 \%$, in increments of $0.5 \%$ ) (Yang and Cho 2008). To examine $\mathrm{O}_{2}$ metabolism, growth under strictly anaerobic conditions was tested on $\mathrm{MA}$ with or without $0.1 \% \mathrm{NaNO}_{3}$ for 7 days at 30 ${ }^{\circ} \mathrm{C}$. Oxidase activity was determined with an oxidase reagent (bioMérieux). Catalase activity was tested by the observation of gas bubble safter the addition of a few drops of $3.0 \%(\mathrm{v} / \mathrm{v}) \mathrm{H}_{2} \mathrm{O}_{2}$ to fresh biomass grown on an agar plate. Antibiotic susceptibility tests were performed by the disc-diffusion method on MA according to the protocol of Du et al. (2014). The presence of PHB granules were determined according to the protocols of Ostle et al. (1982). According to the manufacturers' instructions, the oxidation and fermentation of carbohydrates were determined after growth on MA at $30^{\circ} \mathrm{C}$ for 2 days using the Biolog GEN III Micro Plates and API 50CHB Fermentation Kit (bioMérieux). Other physiological tests were carried out using API 20E, API 20NE, and API ZYM strips (bioMérieux).

Chemotaxonomic characterisation

Chemotaxonomic characteristics of strain $\mathrm{G} 4^{\top}$ and the reference strain were determined under similar conditions. Fatty acid extraction and analyses were performed according to procedures described by Sasser (1990) with a Microbial Identification system (MIDI; Microbial ID). The respiratory isoprenoid quinones were purified according to the protocol described by Hiraishi et al. (1996) and analysed using HPLC. Polar lipid analysis was performed by the Marine Culture Collection of China (MCCC), Xiamen, Fujian Province, P. R. China.

\section{Results And Discussion}

Phylogenetic analysis and genome sequencing

Analysis of the $16 \mathrm{~S}$ rRNA gene sequences revealed that strain $\mathrm{G}^{\top}$ belonged to the genus Oceaniglobus, within the family Rhodobacteraceae. Strain $\mathrm{G}^{\top}$ shared the highest sequence similarity with $O$. ichthyenteri (96.6\%), followed by O.indicus (95.3\%). The neighbour-joining phylogenetic tree (Fig. 1) revealed that strain $\mathrm{G}^{\top}$, $O$. ichthyenteri and $O$. indicus formed an monophyletic cluster, with high 
bootstrap support (99\%). It indicated that strain $\mathrm{G} 4^{\top}$ might represent a novel species of the genus Oceaniglobus.

The genome of strain $\mathrm{G} 4^{\top}$ was comprised of 4472 genes and 33 contigs with a total length of 4588953 bp. The main coverage was $360 \times$. The N50 value was $226458 \mathrm{bp}$. There were $5 \mathrm{~S}$ rRNAs of 3, 16S rRNA of 2, 23S rRNAs of 2, tRNAs of 47 and sRNAs of 3. Complete genome analysis revealed that the 4,099 protein-coding genes constituted $91.7 \%$ of the total genes in the genome. Furthermore, there were 3,965 genes (88.7\%) connected to KEGG pathways, 3,320 genes (74.2\%) assigned to 24 different clusters of orthologous groups (COGs) and 1,458 genes (32.6\%) connected to SwissProt pathways. Based on the genome sequence annotation, the genome contained several genes coding for Glycoside Hydrolases (GHs), Glycosyl transferases (GTs) and Carbohydrate esterases (CEs). There were 3965 genes annotated by KEGG pathway annotation, involving cellular Processes, environmental information processing, genetic information processing, human diseases, metabolism and organismal systems and a large number of genes were found to be focus on metabolism and membrane transport. The genes that encoded the enzymes required for PHB synthesis were present in the genome, the presence of genes encoding phaZ (EC3.1.1.75) and phaC (EC 2.3.1.-) showed the metabolic capacity of strain $\mathrm{G} 4^{\top}$ to accumulate PHB intracellularly.

According to the genome sequence, the DNA G + C content was $65.3 \mathrm{~mol} \%$, which was higher than the related strains 0 . indicus $(59.0 \mathrm{~mol} \%$ ) and 0 . ichthyenteri (64.2 mol\%). The AAI values were $71.3 \%$ with 0 . indicus and $75.0 \%$ with 0 . ichthyenteri, which were far below the $90 \%$ cut-off value for prokaryotic species delineation (Rodriguez-R and Konstantinidis 2014). AAl values of $71.3 \%$ and $75.0 \%$ indicated that strain $\mathrm{G}^{\top}{ }^{\top}$ represents a new species. The ANI values were $76.4 \%$ with 0 . indicus and $76.3 \%$ with 0 . ichthyenteri, which were lower than the 95-96\% cut-off value for species demarcation (Richter and Rossello-Mora 2009). The dDDH values were $20.0 \%$ with $O$. indicus, $19.4 \%$ with $O$. ichthyenteri, which were below the standard cut-off value (70\%) (Meier-Kolthoff et al. 2013). These results confirmed that strain G4 ${ }^{\top}$ represented a novel species of the genus Oceaniglobus.

Morphology, physiology, and biochemical analysis

Cells were Gram-stain negative, aerobic, motile, gliding, lacking flagella, and oval (0.5-0.8 $\mu \mathrm{m}$ in width, 0.6-1.0 $\mu \mathrm{m}$ in length) (Fig. S1). Colonies were $0.8-1.0 \mathrm{~mm}$ in diameter, creamy, circular and convex with smooth surfaces after incubation on $\mathrm{MA}$ at $30^{\circ} \mathrm{C}$ for 2 days. $\mathrm{NaCl}$ was not essential for growth, which distinguished strain $\mathrm{G} 4^{\top}$ from the related strains, $O$. ichthyenteri and $O$. indicus. The accumulation of PHB granules was observed by fluorescence microscopy. Besides, it was sensitive to ampicillin, penicillin, erythromycin, chloramphenicol, ciprofloxacin, gentamicin and cefazolin. Other phenotypic characteristics of the strain $\mathrm{G}^{\top}$ and related strains are shown in Table 1.

Chemotaxonomic characterisation 
The major fatty acid was summed feature $8\left(\mathrm{C}_{18: 1} \omega 7 c\right.$ and/or $\left.\mathrm{C}_{18: 1} \omega 6 c\right)$. The cellular fatty acid composition was similar to that of the related taxa of the genus Oceaniglobus. The detailed results of the fatty acids are shown in Table 2. The sole isoprenoid quinone found in strain $\mathrm{G} 4^{\top}$, ubiquinone-10 (Q-10), was in accordance with the properties of the genus Oceaniglobus. The polar lipid components of strain $\mathrm{G} 4^{\top}$ were iphosphatidylglycerol, phosphatidylcholine, phosphatidylethanolamine, phosphatidylglycerol and phosphatidyldimethylethanolamine. Further detailed polar lipid images of the different strains are given in Fig. S1 (available in the online version of this article).

\section{Conclusion}

The combined results of the phylogenetic and chemotaxonomic analyses supported that it is reasonable to assign strain $\mathrm{G} 4^{\top}$ as a member of the genus Oceaniglobus. Strain $\mathrm{G} 4^{\top}$ was distinguished from the type strain of $O$. indicus by differences in several phenotypic characteristics, including growth without $\mathrm{NaCl}$, activity of some enzymes and susceptibility to some antibiotics (Table 1). On the basis of the phenotypic chemotaxonomic phylogenetic and genetic data, therefore, strain $\mathrm{G}^{\top}$ is considered to represent a novel species of the genus Oceaniglobus, for which the name Oceaniglobus trochenteri sp. nov. is proposed.

\section{Description of Oceaniglobus trochenteri sp. nov.}

Oceaniglobus trochenteri (troch.en'te.ri. N.L. masc. n. Trochus a conch genus; Gr. neut. n. enteron gut; N.L. gen. n. trochenteri of a conch gut).

Cells are Gram-stain negative, catalase-positive, oxidase-positive, motile, non-flagellated and ovoidshaped, approximately $0.5-0.8 \mu \mathrm{m}$ wide and 0.6-1.0 $\mu \mathrm{m}$ long. Colonies are elevated with a smooth surface, beige-pigmented and uniformly circular with a diameter of approximately $0.8-1.0 \mathrm{~mm}$ after incubation on $\mathrm{MA}$ at $30^{\circ} \mathrm{C}$ for 2 days. The $\mathrm{pH}$ and temperature ranges for growth are $\mathrm{pH}$ 6.0-9.0 and 4$42^{\circ} \mathrm{C}$ (optimum at $\mathrm{pH} 6.5-7.0$ and $25-30^{\circ} \mathrm{C}$ ). Growth occurs in the presence of $0.0--11.0 \% \mathrm{NaCl}$ (optimum 2.0-3.0\%). Cells hydrolyze Tween 40, cellulose, agar and starch, but not alginate. Acids are produced from glycerol, aesculin, L-rhamnose, L-xylose, L-fucose, D-arabinose, D-lyxose, D-ribose, Dxylose, D-fructose and D-fucose. It is positive for alkaline phosphatase, esterase (C4), esterase lipase (C8), leucine arylamidase, valine arylamidase, cystine arylamidase, acid phosphatase, naphthol-AS-BIphosphohydrolase, $a$ and $\beta$-galactosidase, $a$ and $\beta$-glucosidase. but negative for lipase (C14), trypsin, $\beta$ glucuronidase, $\mathrm{N}$-acetyl- $\beta$-glucosaminidase, $\alpha$-mannosidase, and $\alpha$-fucosidase. Carbon source oxidation tests show positive results for trehalose, maltose, cellobiose, sucrose, lactose, raffinose, N-acetyl-Dglucoside, D-glucose, D-mannose, D-fructose, D-galactose, D-fucose, myo-inositol and D-gluconic acid. All negative traits of commercial kits are given in Table S1. The sole isoprenoid quinone is Q-10. The major cellular fatty acid is summed feature $8\left(\mathrm{C}_{18: 1} \omega 7 c\right.$ and/or $\left.\mathrm{C}_{18: 1} \omega 6 c\right)$. The polar lipid profile consists of diphosphatidylglycerol, phosphatidylcholine, phosphatidylethanolamine, phosphatidylglycerol and phosphatidyldimethylethanolamine. The DNA G + C content is $65.3 \mathrm{~mol} \%$. 
The type strain, $\mathrm{G}^{\top}{ }^{\top}\left(=\mathrm{MCCC} 1 \mathrm{~K} 04356^{\top}=\mathrm{KCTC} 82506^{\top}\right.$ ) was isolated from gut microflora of top shell collected from Diwanggong market, at Weihai, Shandong Province, People's Republic of China.

The GenBank/EMBL/DDBJ accession number for the $16 \mathrm{~S}$ rRNA gene sequence of strain $\mathrm{G}^{\top}{ }^{\top}$ is MW555789 and the number for the whole genome sequence is JACNMM000000000.

\section{Abbreviations}

AAl Average Amino Acid identity

ANI Average Nucleotide Identity

Dddh digital DNA-DNA Hybridization

HPLC High Performance Liquid Chromatography

HEPES N-(2Hydroxyethyl)Piperazine-N'-2-Ethanesulfonic Acid

CAPSO 3-Cyclohexylamino-2-Hydroxypropanesulfonic Acid Sodium Salt

MES 2-(N-Morpholino) ethane-sulfonic acid

PIPES Piperazine-1,4-Bisethanesulfonic Acid

Tricine N-[Tris(Hhydroxymethyl)Methyl] Glycine

KCTC Korean Collection for Type Cultures

KEGG Kyoto Encyclopedia of Genes and Genomes

MA Marine agar 2216; MB, Marine broth 2216

MEGA Molecular Evolutionary Genetics Analysis

MCCC Marine Culture Collection of China

PHB poly- $\beta$-hydroxybutyrate.

\section{Declarations}

\section{Funding information}

This work was supported by the National Natural Science Foundation of China (31700116), the Natural Science Foundation of Shandong Province (ZR2017MC019), the China Postdoctoral Science Foundation (2183), and the Key Science and Technology Program of Weihai (1070413421511). 


\section{Conflicts of interest}

Authors declare that there is no conflict of interest.

\section{Data availability statement}

All data generated or analysed during this study are included in this published article, its supplementary information files and GenBank/EMBL/DDBJ. The GenBank/EMBL/DDBJ accession number for the $16 \mathrm{~S}$ rRNA gene sequence of strain $\mathrm{G}^{\top}{ }^{\top}$ is MW555789 and the number for the whole genome sequence is JACNMM000000000. Supplementary figures and Supplementary tables are available with the online version of this paper.

\section{Authors' contributions}

YXZ designed research and project outline. RY and ZC performed isolation, deposition, and identification. STY and MJZ performed genome analysis. ZC drafted the manuscript. All authors read and approved the final manuscript.

\section{Acknowledgement}

We are grateful to Prof. Aharon Oren (The Hebrew University of Jerusalem, Israel) for helping with the etymology.

\section{References}

1. Aziz RK, Bartels D, Best AA, Dejongh M, Disz T, Edwards RA, Formsma K, Gerdes S, Glass EM, Kubal $M$, Meyer F, Olsen GJ, Olson R, Osterman AL, Overbeek RA, Mcneil LK, Paarmann D, Paczian T, Parrello B, Pusch GD, Reich C, Stevens R, Vassieva O, Vonstein V, Wilke A, Zagnitko O (2008) The RAST server: Rapid annotations using subsystems technology. Bmc Genomics 9:75

2. Blin K, Shaw S, Steinke K, Villebro R, Ziemert N, Lee SY, Medema MH, Weber T (2019) antiSMASH 5.0: updates to the secondary metabolite genome mining pipeline. Nucleic Acids Res 47:W81-W87

3. Bowman JP (2000) Description of Cellulophaga algicola sp nov., isolated from the surfaces of Antarctic algae, and reclassification of Cytophaga uliginosa (ZoBell and Upham 1944) Reichenbach 1989 as Cellulophaga uliginosa comb. nov. Int J Syst Evol Microbiol 50:1861-1868

4. Consortium (2019) UniProt: a worldwide hub of protein knowledge. Nucleic Acids Res 47:D506D515

5. Du ZJ, Wang Y, Dunlap C, Rooney AP, Chen GJ (2014) Draconibacterium orientale gen. nov., sp nov., isolated from two distinct marine environments, and proposal of Draconibacteriaceae fam. nov. Int $J$ Syst Evol Microbiol 64:1690-1696

6. Felsenstein J (1981) Evolutionary Trees from DNA-Sequences - a Maximum-Likelihood Approach. J Mol Evol 17:368-376 
7. Felsenstein J (1985) Confidence-Limits on Phylogenies - an Approach Using the Bootstrap. Evolution 39:783-791

8. Fitch WM (1971) Toward Defining the Course of Evolution: Minimum Change for a Specific Tree Topology. Syst Biol 20:406-416

9. Hiraishi A, Ueda Y, Ishihara J, Mori T (1996) Comparative lipoquinone analysis of influent sewage and activated sludge by high-performance liquid chromatography and photodiode array detection. $\mathrm{J}$ Gen Appl Microbiol 42:457-469

10. Kanehisa M, Sato Y, Kawashima M, Furumichi M, Tanabe M (2016) KEGG as a reference resource for gene and protein annotation. Nucleic Acids Res 44:D457-D462

11. Kim OS, Cho YJ, Lee K, Yoon SH, Kim M, Na H, Park SC, Jeon YS, Lee JH, Yi H, Won S, Chun J (2012) Introducing EzTaxon-e: a prokaryotic 16S rRNA gene sequence database with phylotypes that represent uncultured species. Int J Syst Evol Microbiol 62:716-721

12. Kumar S, Stecher G, Tamura K (2016) MEGA7: Molecular Evolutionary Genetics Analysis Version 7.0 for Bigger Datasets. Mol Biol Evol 33:1870-1874

13. Li JY, Huang ZB, Lai QL, Liu XP, Wang GY, Shao ZZ (2017) Oceaniglobus indicus gen. nov., sp nov., a member of the family Rhodobacteraceae isolated from surface seawater. Int J Syst Evol Microbiol 67:4930-4935

14. Liu CL, Shao ZZ (2005) Alcanivorax dieselolei sp. nov., a novel alkane-degrading bacterium isolated from sea water and deep-sea sediment. Int J Syst Evol Microbiol 55:1181-1186

15. Meier-Kolthoff JP, Auch AF, Klenk HP, Göker M (2013) Genome sequence-based species delimitation with confidence intervals and improved distance functions. Bmc Bioinformatics 14:60

16. Ostle AG, Holt JG (1982) Nile Blue A as a fluorescent stain for Poly- $\beta$ - Hydroxybutyrate. Appl Environ Microbiol 44:238-241

17. Park S, Won SM, Kim H, Park DS, Yoon JH (2014) Aestuariivita boseongensis gen. nov., sp nov., isolated from a tidal flat sediment. Int J Syst Evol Microbiol 64:2969-2974

18. Richter M, Rossello-Mora R (2009) Shifting the genomic gold standard for the prokaryotic species definition. Journal of the Agricultural Chemical Society of Japan 106:2637-2638

19. Rodriguez -RLM, Konstantinidis KT (2014) Bypassing cultivation to identify bacterial species: cultureindependent genomic approaches identify credibly distinct clusters, avoid cultivation bias, and provide true insights into microbial species. Microbe:111-118

20. Saitou N, Nei M (1986) The Neighbor-Joining method: a new method for reconstructing phylogenetic trees. Mol Biol Evol 4:406-425

21. Sasser M (1990) Identification of bacteria by gas chromatography of cellular fatty acids. USFCC Newsl 20:1-6

22. Takeshita S, Oda T, Muramatsu T (1991) An Improved Plate Method, in the Presence of Calcium Chloride or Sulfuric Acid, for Simultaneous Detection of Alginate Lyases. Agric Biol Chem 55:26372638 
23. Tindall BJ, Sikorski J, Smibert RA, Krieg NR (2007) Phenotypic Characterization and the Principles of Comparative Systematics. In: Reddy CA, Beveridge TJ, Breznak JA, Marzluf G, Schmidt TM et al. (ed). Methods for General and Molecular Microbiology, 3rd edn. Washington, DC.pp330-393

24. Wang NN, Zhou LY, Wang XP, Li YX, Du ZJ (2019) Oceaniglobus ichthyenteri sp. nov., isolated from the gut microflora of sea bass (Dicentrarchus labrax L.) and emended description of the genus Oceaniglobus. Int J Syst Evol Microbiol 69:2892-2898

25. Yang SJ, Cho JC (2008) Gaetbulibacter marinus sp nov., isolated from coastal seawater, and emended description of the genus Gaetbulibacter. Int J Syst Evol Microbiol 58:315-318

26. Yoon SH, Ha SM, Kwon S, Lim J, Kim Y, Seo H, Chun J (2017a) Introducing EzBioCloud: a taxonomically united database of $16 \mathrm{~S}$ rRNA gene sequences and whole-genome assemblies. Int $\mathrm{J}$ Syst Evol Microbiol 67:1613-1617

27. Yoon SH, Ha SM, Lim J, Kwon S, Chun J (2017b) A large-scale evaluation of algorithms to calculate average nucleotide identity. Antonie Van Leeuwenhoek 110:1281-1286

\section{Tables}

Table 1. Differential characteristics of strain $\mathrm{G} 4^{\top}$ and other closely related members of the genus Oceaniglobus.

Strains: $1, \mathrm{G}^{\top}$; 2 , O. indicus MCCC $1 \mathrm{~A}_{11863^{\top}} ; 3$, O. ichthyenteri MCCC $1 \mathrm{H}^{0} 00318^{\top}$. +, Positive; -, negative; $\mathrm{W}$, weak. All data from this study except DNA G+C contents of the related strains, which were from the original species description: 


\begin{tabular}{|c|c|c|c|}
\hline Characteristic & 1 & 2 & 3 \\
\hline Isolation source & Gut of snail & Seawater & Gut of sea bass \\
\hline \multicolumn{4}{|l|}{ Growth range(optimum) } \\
\hline $\mathrm{NaCl}(\mathrm{w} / \mathrm{v}, \%)$ & $\begin{array}{l}0.0-11.0(3.0- \\
4.0)\end{array}$ & $\begin{array}{l}0.5-10.0(3.0- \\
4.0)\end{array}$ & $\begin{array}{l}1.0-9.0(2.0- \\
3.0)\end{array}$ \\
\hline $\begin{array}{l}\text { Temperature ( } \\
\left.{ }^{\circ} \mathrm{C}\right)\end{array}$ & $4-42(25-30)$ & $5-37(28-35)$ & $4-40(28-30)$ \\
\hline $\mathrm{pH}$ & $6.0-9.0(6.5-7.0)$ & $\begin{array}{l}5.0-10.0(7.0- \\
8.0)\end{array}$ & $6.0-9.5(7.0-7.5)$ \\
\hline Nitrate reduction & - & + & - \\
\hline Hydrolysis of starch & + & - & + \\
\hline \multicolumn{4}{|c|}{$\begin{array}{l}\text { Acids production from (API } 50 \\
\text { CHB): }\end{array}$} \\
\hline Glycerol & + & - & - \\
\hline D-glucose & + & - & - \\
\hline L-Arabinose & + & - & + \\
\hline D-mannose & + & - & + \\
\hline Maltose & + & - & + \\
\hline Sucrose & + & - & + \\
\hline \multicolumn{4}{|c|}{ Enzymic activities (API ZYM): } \\
\hline Alkaline phosphatase & + & - & + \\
\hline a-chymotrypsin & - & - & + \\
\hline Acid phosphatase & + & + & - \\
\hline \multicolumn{4}{|c|}{ Oxidation of (Biolog GEN III): } \\
\hline Cellobiose & + & - & + \\
\hline$a$-ketoglutaric acid & + & - & + \\
\hline D-fructose & + & - & + \\
\hline myo-inositol & + & - & + \\
\hline D-maltose & + & - & + \\
\hline D-trehalose & + & - & + \\
\hline L-rhamnose & + & + & - \\
\hline
\end{tabular}




\begin{tabular}{|llll|} 
D-galacturonic acid & + & + & - \\
\hline D-glucuronic acid & + & + & - \\
\hline DNA G+C content (mol\%) & 65.3 & $64.2^{\mathrm{a}}$ & $59.0^{\mathrm{b}}$ \\
\hline
\end{tabular}

a Data from Li et al. (2017)

b Data from Wang et al. (2019)

Table 2. Cellular fatty acid composition of strain $\mathrm{G} 4^{\top}$ and the closest relatives.

Strains: $1, \mathrm{G} 4^{\top} ; 2,0$. indicus MCCC $1 \mathrm{~A} 11863^{\top} ; 3,0$. ichthyenteri MCCC $1 \mathrm{H} 00318^{\top}$. All data were taken from this study. TR, Traces ( $<1.0 \%)$; - , not detected. Fatty acids amounting to $<1.0 \%$ of the total fatty acids in both strains are not shown.

\begin{tabular}{|c|c|c|c|}
\hline Fatty acid & 1 & 2 & 3 \\
\hline \multicolumn{4}{|l|}{ Straight-chain: } \\
\hline$C_{16: 0}$ & 10.97 & 6.15 & 8.27 \\
\hline$C_{17: 0}$ & TR & 1.36 & $\mathrm{TR}$ \\
\hline$C_{18: 0}$ & 3.05 & 1.35 & 1.94 \\
\hline \multicolumn{4}{|c|}{ Unsaturated fatty acids } \\
\hline$C_{20: 2} \omega 6,9 c$ & $\mathrm{TR}$ & $\mathrm{TR}$ & - \\
\hline $\mathrm{C}_{19: 0} \mathrm{cyclo} \omega 8 \mathrm{C}$ & 18.70 & 20.56 & - \\
\hline $\mathrm{C}_{18: 1} \omega 7 c 11$-methyl & 3.76 & 3.24 & 6.6 \\
\hline \multicolumn{4}{|l|}{ Hydroxy fatty acids } \\
\hline $\mathrm{C}_{10: 0} 3-\mathrm{OH}$ & 2.81 & 2.74 & 3.62 \\
\hline $\mathrm{C}_{12: 0} 3-\mathrm{OH}$ & 1.05 & $\mathrm{TR}$ & 3.02 \\
\hline Summed feature $3^{*}$ & TR & 1.12 & 1.52 \\
\hline Summed feature $7^{\#}$ & $\mathrm{TR}$ & 1.87 & - \\
\hline Summed feature $8^{\&}$ & 55.12 & 54.87 & 67.47 \\
\hline
\end{tabular}

*Summed feature 3, $\mathrm{C}_{16: 1} \omega 7 c$ and/or $\mathrm{C}_{16: 1} \omega 6 c$.

\#Summed feature 7, un 18.846 and/or $C_{19: 1} \omega 6 c$. 
\&Summed feature 8, $\mathrm{C}_{18: 1} \omega 6 \mathrm{c}$.

\section{Figures}

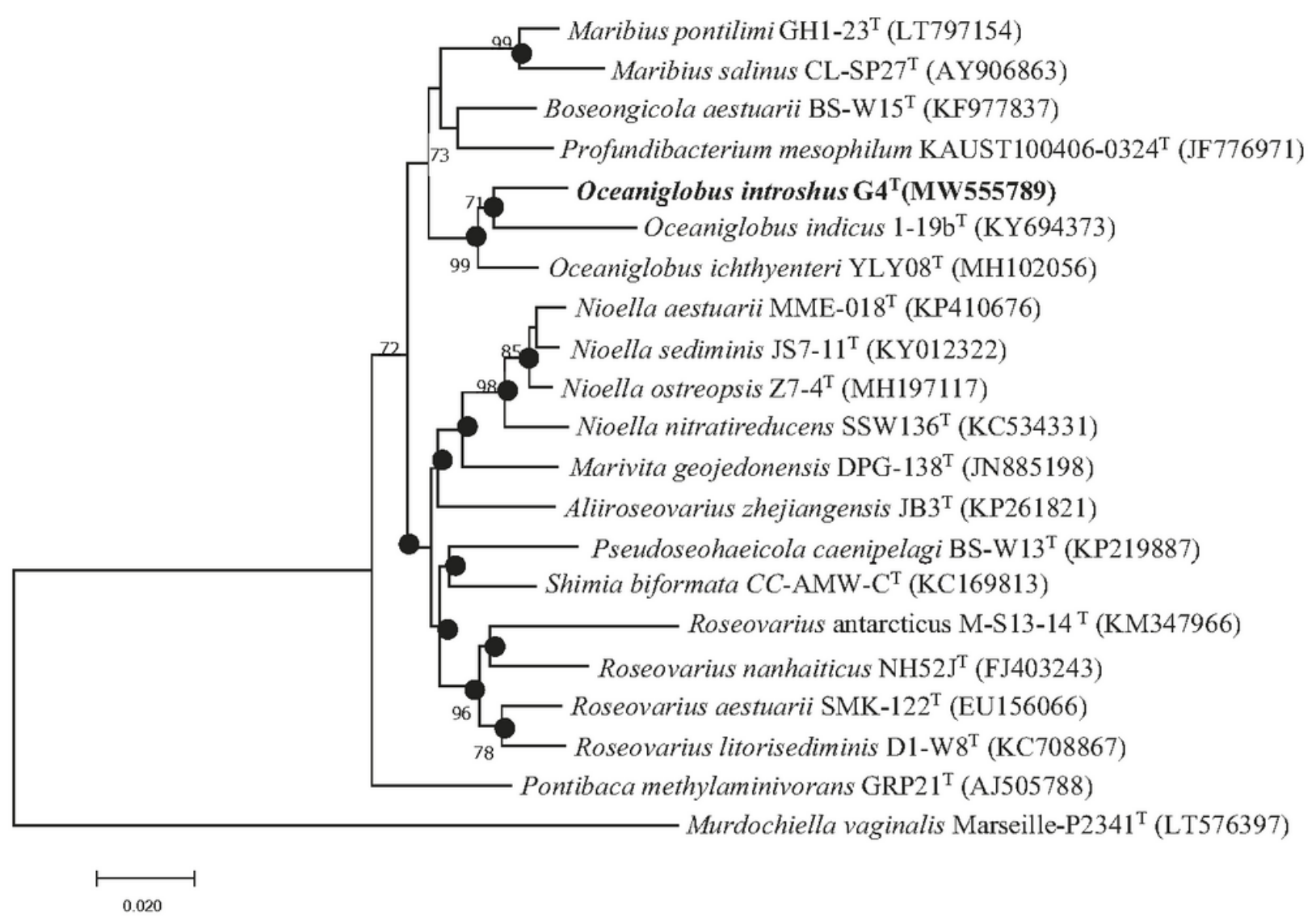

\section{Figure 1}

Neighbor-joining phylogenetic tree based on 16S rRNA gene sequences of strain G4T and high similarity of genus. Bootstrap support values (1000 replications) above $50 \%$ are shown at nodes. Filled circles 
indicate nodes that were also recovered in maximum-likelihood and neighbor-joining phylogenetic trees based on the same sequences. Murdochiella vaginalis Marseille-P2341T was used as an outgroup. Bar, 0.02 substitutions per nucleotide position.

\section{Supplementary Files}

This is a list of supplementary files associated with this preprint. Click to download.

- SupplementaryMaterials.docx 